\title{
Inclusion of Bioethics in Performance Appraisal for Promoting Ethical Behaviour among Doctors in Hospital
}

\author{
Deepak Singla ${ }^{1}$, Bharathi Saxena ${ }^{2}$, Amit Mahajan $^{3}$ \\ ${ }^{1}$ Medical Director; Maharaja Agrasen Hospital, Punjabi Bagh, New Delhi. \\ ${ }^{2}$ Joint Medical Superintendent, Maharaja Agrasen Hospital, Punjabi Bagh, New Delhi. \\ ${ }^{3} \mathrm{PhD}$ Research Scholar, Manav Rachna University, Faridabad \\ Corresponding Author: Deepak Singla \\ E-mail: singla1960@gmail.com
}

\begin{abstract}
The growing public concern about the ethical conduct of healthcare professionals, specially the doctors, highlights the need to incorporate clinical ethics in all wakes of medicine be it medical education, CMEs (Continuing Medical Education), working and even performance appraisal. Bioethics, being a new subject, at least for the medical fraternity in India, needs lot of initiatives to reach all the aspects of clinical practice of doctors. One method to ensure that the doctors working in the hospital are following ethical behavior and are aware about the ethical issues in the hospital is to incorporate the 'Ethics Knowledge and Practice by Doctors' in the performance appraisal. The aim of the study is to examine the applicability of 'Ethics Knowledge and Practice by Doctors' in performance appraisal of the doctors so that ethical behavior of doctors could be positively impacted.

This article is based on the secondary research and literature is reviewed from different academic sources which includes articles and previous research being done by other researchers. Existing body of research highlighted that Ongoing Professional Practice Evaluation (OPPE) method is newest model to conduct performance appraisal of doctors. For conducting OPPE six parameters are examined, viz. Patient Care; Medical and clinical knowledge; Practice based leaning and improvement; Interpersonal and Communication Skills; Professionalism; and, System based practice. Ongoing Professional Practice Evaluation (OPPE) method is found to be most comprehensive method to conduct performance appraisal of the doctors. 'Ethics Knowledge and Practice by Doctors' could be added in 'Professionalism' parameter of OPPE.
\end{abstract}

Keywords: Bioethics, performance appraisal, ethical behavior, hospital, appraisal, OPPE.

\section{INTRODUCTION}

India medical scenario is seeing a new trend where the healthcare institutions and providers are facing lot of litigation and customers' unrest against the unethical practices. Wynia noted in his article that patients do care about ethics [1]. In India, also, it is observed that the public awareness has increased and the customers are looking for unethical practices followed by the hospitals or the doctors; although many a times the facts are different than belief. The growing public concern about the ethical conduct of healthcare professionals, specially the doctors, highlights the need to 
incorporate clinical ethics in medical education including CMEs. The doctors are supposed to know and follow ethical principles while practicing [2].

Bioethics, being a new subject, at least for the medical fraternity in India needs lot of educational initiatives. The medical colleges are promoting bioethics teaching as a part of their curriculum after Medical Council of India (MCI) had directed the medical institutions to incorporate bioethics and ethical practices in their teaching schedule with the subject name of 'Attitude, Ethics and Communication' [3-4]. The new generation of doctors, who are just graduated or will be graduating in coming years, are sensitized toward ethics and ethical practices but the practicing doctors are still lacking the same. Many initiatives are started for the practicing doctors by the hospital with the help of external agencies like, UNESCO Chair in Bioethics (Haifa) [5]. To improve ethics quality in healthcare, hospitals need a way to identify whether ethical practices throughout the hospital are consistent with accepted ethics standards, norms, and expectations for the hospital and its employees.

Healthcare personnel frequently face ethically difficult situations in the course of their work and these issues cover a wide range of areas in clinical practice. One method to ensure that the doctors working in the hospital are following ethical behaviour and are aware about the ethical issues in the hospital is to incorporate the 'Ethics Knowledge and Practice by Doctors' in the performance appraisal [7]. This article dwells on this premise that by incorporating the 'Ethics' in performance appraisal of the doctors the ethical behaviour of the doctors could be positively impacted. To understand the applicability of ethics in performance appraisal it is helpful to understand the concept of performance appraisal and how the same is used for doctors. The subsequent paragraphs explained the same.

Performance appraisal is one of the important components in the rational and systematic process of human resource management. Performance appraisal can be defined as a performance review, performance evaluation and career development of employee. Performance appraisal is process of evaluating or reviewing the performance of an employee. It is the process of evaluation of how well employees perform their jobs and then communicating that information to the employee. Performance Appraisal is a formal systematic review and evaluation of individual or team performance. Performance in any type of industry is performed to evaluate the performance of employee, the need of training, the area of improvement, decision of increment and promotion, the parameters for selecting the right candidate with right qualities [7]. Performance Appraisal is a goal-oriented process directed towards ensuring that organization process is in place to maximize the productivity of employee, teams and ultimately, the organization. Performance Appraisal is a formal system of review and evaluating of individual or team task performance [8].

Without a reliable performance appraisal system, a human resource management system falls apart, resulting in the total waste of the valuable human assets a company has. Performance appraisal cannot be implemented successfully unless it is accepted by all concerned.

\section{Performance Appraisal in A Hospital}

Performance appraisal in a hospital should be done with primary motive to improve the quality of healthcare. Hospital is a different industry as compare to other service sector industries because of the variety of different skilled workers working in the hospital ranging from doctors to housekeeping staff. The major difference from the other industry is that hospital deals with the lives of the patient; so, for the satisfaction of the patients the employees' performance need to be up to the mark which require a regular performance appraisal. The hospital is accountable to patients and the community for providing quality services [9].

In the hospital patient is the most important person; therefore, all the employees of the hospital have to perform their duties in a way to get maximum patient satisfaction. It is equally essential to deal with patient and their relatives in the best possible manner to enhance the satisfaction. If the 
performance of employees is appraised then it is very beneficial for both the employees and the management and easier to understand the current performance level and the area of improvements [10]. Also, performance appraisal helps to identify training needs of the employees so that they can be trained to improve their performance. This leads to customer satisfaction and overall organization development.

Performance appraisal in a hospital is very different from other industries in many ways. There are doctors from different specialities; allied healthcare staff like the nurses, pharmacy, technician; and administrative staff, like, the Reception, HR, Quality, and Finance department, of which the performance appraisal should be conducted. As there are different people with different duties and roles and responsibility so performance appraisal needs to conducted in a different way and with different parameter to have effective evaluation and for better judgment of area to improvement of both employee and hospital as a whole and the decision of judgment.

In a hospital the performance appraisal can be conducted by various methods. There are different types of staff working in the hospital with different roles and responsibility which need different type of evaluation system. The general administrative staff could be appraised by any of the established methods like 360 degree, Behaviourally Anchored Rating Scales, Management by Objectives (MBO) Method. The nursing staff, technicians, and doctors need specialized performance appraisal system. Competence mapping system is generally adopted for nursing staff and technicians as a performance appraisal tool [7,9]. For doctors specialized performance appraisals are tools are utilized all across the globe [10-11]. One of the newest and most comprehensive tool for doctors' performance appraisal is 'Ongoing Professional Practice Evaluation' (OPPE).

For conducting OPPE there are some parameters that need to be examined first. These parameters are relevant for the doctors to evaluate the performance in a right and a specific way, according to the complexity of the job. The parameters are Patient Care; Medical and clinical knowledge; Practice based leaning and improvement; Interpersonal and Communication Skills; Professionalism and System based practice [12]. OPPE is ongoing data collection for performance appraisal for the doctors. After conducted OPPE, the need of FPPE arises if require by any employee. FPPE is a more focus evaluation on an employee. When OPPE is done, the need of FPPE arises. After performing OPPE, if the supervisor requires the need to focus on a specific area then FPPE is used. FPPE focuses on the area that need to focus more, the areas that require more attention and improvement.

\section{OPPE at Maharaja Agrasen Hospital}

\begin{tabular}{|l|l|}
\hline Parameters & Aspects \\
\hline Patient Care & 10 \\
\hline Medical/Clinical Knowledge & 8 \\
\hline Systems Based Practice & 6 \\
\hline Practice Based Learning and Improvement & 4 \\
\hline Interpersonal Communications & 3 \\
\hline Professionalism & 8 \\
\hline Total & $\mathbf{3 9}$ \\
\hline
\end{tabular}

Maharaja Agrasen Hospital (MAH) embraced OPPE after getting accreditation from JCI as a quality tool to enhance the capabilities of performance appraisal being done in the hospital. 
Performance appraisal of doctors/consultants is one of the most difficult tasks to perform by administrators and HR department. The doctors' performance needs to be examined on different parameters which cannot be captured using prevalent performance appraisal tools; hence, MAH had decided to adopt OPPE to measure the performance of the doctors/consultants.

As mentioned above, there are six parameters on which the doctors are to be rated using different aspects. These are Patient Care; Medical and clinical knowledge; Practice based leaning and improvement; Interpersonal and Communication Skills; Professionalism and System based practice. Each parameter consists of different aspects which are objectively measured using data from different audit reports and different departmental reports.

MAH decided to measure the performance of the doctors/consultants using ethical aspects also. For doing this, many ethical aspects are captured and being used to appraise the doctors' performance. Some of the key aspects are: Goal of Treatment Documented, Medication Errors due to Wrong Prescription, Medication Errors in OPD Prescription, Adverse Drug Event due to Prescription Error, Sentinel Event, Counselling done \& documented, Compliance of Consents taken and financial counselling regarding the treatment cost. These aspects are captured and proper criterion is set to give marks to the data

\begin{tabular}{|c|c|c|c|}
\hline \multicolumn{4}{|c|}{$\begin{array}{l}\text { Systems Based Practice } \\
\text { Demonstrates both an understanding of the contexts and systems in which health care is provided, and the ability to apply this knowledge tc } \\
\text { improve and optimize health care. }\end{array}$} \\
\hline & Criteria & Data & Score \\
\hline \multicolumn{4}{|l|}{ ALOS } \\
\hline \multicolumn{4}{|l|}{ LAMA Cases } \\
\hline \multicolumn{4}{|l|}{ Return to Casualty within $72 \mathrm{hrs}$} \\
\hline \multicolumn{4}{|c|}{ Medication Errors due to Wrong Prescription } \\
\hline \multicolumn{4}{|c|}{ Medication Errors in OPD Prescription } \\
\hline Number of Referred Patients & & & \\
\hline
\end{tabular}

The objectivity of the data is maintained by using the same assessment criteria for all. One such example is discussed below:

\begin{tabular}{|c|c|c|}
\hline \multicolumn{3}{|c|}{$\begin{array}{l}\text { Systems Based Practice } \\
\text { Demonstrates both an understanding of the contexts and systems in which health care is provided, and the ability to apply this knowledge to improve } \\
\text { and optimize health care }\end{array}$} \\
\hline & Criteria & Measure \\
\hline ALOS & No Score & \\
\hline LAMA Cases & No Score & \\
\hline Medication Errors due to Wrong Prescription & $\begin{array}{l}1 \text { to } 10 \text { Error }=(-) 1 \\
\text { More than } 10=(-) 2\end{array}$ & Number \\
\hline Medication Errors in OPD Prescription & $\begin{array}{l}1 \text { to } 10 \text { Error }=(-) 1 \\
\text { More than } 10=(-) 2\end{array}$ & Number \\
\hline Number of Referred Patients & $\begin{array}{l}\text { Patients Referred in one year } \\
\text { Less than } 5=0 \\
5 \text { to } 10=1 \\
11 \text { to } 20=2 \\
21 \text { to } 30=3 \\
31 \text { to } 40=4 \\
\text { More than } 40=5\end{array}$ & Number \\
\hline
\end{tabular}




\section{CONCLUSION}

Using this methodology, the assessment not only becomes objective but also focused and effective. The doctors are given a format of OPPE tool at the time of appointment so that they know how their work will be assessed. This way the doctors become more responsible and ethical practices are improved.

\section{Further Scope of Research}

This study used OPPE method and adopted the same after making necessary changes as per the requirements of MAH. The collection of data was specifically for one hospital. This research should be done on a larger scale with many hospitals participating in the research. Moreover, the research was a cross-sectional research; whereas, to determine the impact of including ethical practices in performance appraisal needs scientific tool to measure the ethical practice quantitatively. The tool to measure ethical practices quantitatively is still to be developed.

\section{REFERENCES}

1. Wynia MK. Performance measures for ethics quality. Effective Clin Pract (ECP) 1999;2(6):294-8.

2. Subramanian T, Mathai AK, Kumar N. Knowledge and practice of clinical ethics among healthcare providers in a government hospital, Chennai. Indian J Med Ethics 2013;2:96-100.

3. Zayapragassarazan Z, Kumar S, Kadambari D. Record Review of Feedback of Participants on Attitude, Ethics and Communication Module (AETCOM) Proposed by Medical Council of India (MCI). Online Submission 2019;11(1):43-8.

4. Arakal AK. MBBS syllabus revised after 21 years. Deccan Chronicle. [newspaper on the Internet] 2018 Nov Thursday [2018/11/8].

5. Deshpande SN. The UNESCO movement for bioethics in medical education and the Indian scenario. Indian J Psychiatry 2016;58(4):359-62.

6. Fanelli S, Lanza G, Zangrandi A. Competences management for improving performance in health organizations: The Niguarda Hospital in Milan. Int J Health Qual Assur 2018;31(4):337-49.

7. Edmonstone J. Appraising the state of performance appraisal. Health Manpower Manage 1996;22(6):9-13.

8. Vasset F, Marnburg E, Furunes T. Employees' perceptions of justice in performance appraisals. Nurs Manage 2010;17(2).

9. Coates G. Experiencing performance appraisal in a trust hospital. Electr J Sociol 2000;5(1).

10. Overeem K, Faber MJ, Arah OA, Elwyn G, Lombarts KM, Wollersheim HC, Grol RP. Doctor performance assessment in daily practise: does it help doctors or not? A systematic review. Med Educ 2007;41(11):1039-49.

11. Redman T, Snape E, Thompson D, Yan FK. Performance appraisal in an NHS hospital. Hum Resource Manage J 2000;10(1):48-55.

12. Wocher JC. Ongoing Physician Practice Evaluation (OPPE): Challenges in Implementation in Japan-An Opinion. J Japan Hosp Assoc 2013;32:23-7.

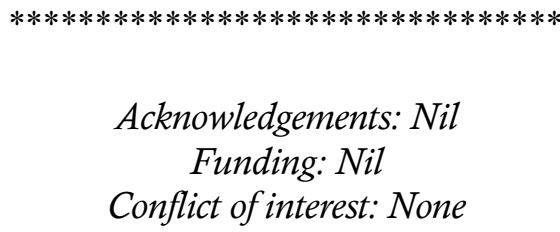

